\title{
Impact of Salicylic Acid Content and Growing Environment on Phytoprostane and Phytofuran (Stress Biomarkers) in Oryza sativa L.
}

\author{
M. Pinciroli, ${ }^{\dagger}$ R. Domínguez-Perles, ${ }^{*}{ }^{\ddagger} \odot$ M. Garbi, ${ }^{\dagger}$ A. Abellán, ${ }^{\ddagger}$ C. Oger, ${ }^{\S}{ }^{\circledR}$ T. Durand, ${ }^{\S}$ J. M. Galano, ${ }^{\S}$ \\ F. Ferreres, ${ }^{+}$and A. Gil-Izquierdo** \\ ${ }^{\dagger}$ Cátedra de Climatología y Fenología Agrícola, Facultad de Ciencias Agrarias y Forestales, Universidad Nacional de la Plata, Calle \\ 60 y 119, 1900 La Plata, Buenos Aires, Argentina \\ ${ }^{\ddagger}$ Research Group on Quality, Safety and Bioactivity of Plant Foods. Department of Food Science and Technology, Centro de \\ Edafología y Biología Aplicada del Segura, Consejo Superior de Investigaciones Científicas, Campus de Espinardo 25, 30100 \\ Espinardo, Spain \\ ${ }^{\S}$ Institut des Biomolécules Max Mousseron, Unité Mixte de Recherche 5247, University of Montpellier, Centre National de la \\ Recherche Scientifique, and École Nationale Supérieure de Chimie de Montpellier, Montpellier, France
}

Supporting Information

ABSTRACT: Phytoprostanes (PhytoPs) and phytofurans (PhytoFs) are oxylipins synthesized by nonenzymatic peroxidation of $\alpha$-linolenic acid. These compounds are biomarkers of oxidative degradation in plant foods. In this research, the effect of environment and supplementation with salicylic acid (SA) on PhytoPs and PhytoFs was monitored by ultra-high-performance liquid chromatography coupled to electrospray ionization and triple quadrupole mass spectrometry (UHPLC-ESI-QqQ-MS/ MS) on seven rice genotypes from Oryza sativa L. subsp. japonica. The plastic cover environment and spray application with 1 and $15 \mathrm{mM}$ SA produced a reduction in the concentration of most of these newly established stress biomarkers [9- $\mathrm{F}_{1 \mathrm{t}}$-PhytoP, ent-16- $\mathrm{F}_{1 \mathrm{t}}$-PhytoP, ent-16-epi-16- $\mathrm{F}_{1 \mathrm{t}}-\mathrm{PhytoP}, 9-\mathrm{D}_{1 \mathrm{t}}$-PhytoP, 9-epi-9- $\mathrm{D}_{1 \mathrm{t}}$-PhytoP, 16- $\mathrm{B}_{1}-\mathrm{PhytoP}, 9-\mathrm{L}_{1}-\mathrm{PhytoP}$, ent-16(RS)-9-epiST- $\Delta^{14}-10$-PhytoF, ent-9(RS)-12-epi-ST- $\Delta^{10}-13$-PhytoF, and ent-16(RS)-13-epi-ST- $\Delta^{14}-9$-PhytoF] by $60.7 \%$ on average. The modification observed in the level of PhytoPs and PhytoFs differed according to the specific oxylipins and genotype, demonstrating a close linkage between genetic features and resistance to abiotic stress, to some extent mediated by the sensitivity of plants to the plant hormone SA that participates in the physiological response of higher plants to stress. Thus, in plants exposed to stressing factors, SA contribute to modulating the redox balance, minimizing the oxidation of fatty acids and thus the syntheis of oxylipins. These results indicated that SA could be a promising tool for managing the thermotolerance of rice crop. However, it remains necessary to study the mechanism of action of PhytoPs and PhytoFs in biochemical processes related to the defense of plants and define their role as stress biomarkers through a nonenzymatic pathway.

KEYWORDS: rice, air temperature, oxidative stress, agronomical practices, biomarkers

\section{INTRODUCTION}

Rice (Oryza sativa L.) is a tropical or subtropical crop featuring high adaptability to diverse environmental conditions. ${ }^{1}$ High temperature impairs grain filling, leading to loss of yield for crops such as rice through decreases in grain size, number, and quality. Thus, considering recent climate change, an understanding of the physiological processes responsible for these effects deserves to be further evaluated. ${ }^{2}$ To date, studies on japonica varieties of rice (Oryza sativa L. subsp. japonica), developed in Japan, have provided information on the optimum air temperature for ripening that ranges between 20 and $25{ }^{\circ} \mathrm{C},{ }^{2,3}$ while air temperature above $30{ }^{\circ} \mathrm{C}$ causes deleterious effects on yield and nutritional quality, as well as modified physicochemical features of the grain. ${ }^{4,5}$ Indeed, in recent decades, varietal differences have been described regarding the sensitivity of rice plants to high temperatures. ${ }^{4}$

Under normal physiological conditions, reactive oxygen species (ROS) are continuously produced in plants as a consequence of cellular metabolism, especially in the photosynthetic process. ${ }^{6}$ Most of these conditions either increase light-driven electron transport or restrict $\mathrm{CO}_{2}$ availability, augmenting ROS production in the chloroplast, associated with photosystems I and II, as well as in peroxisomes, associated with photorespiration. ${ }^{6}$ These radicals are very unstable and react rapidly with other groups or substances, leading to cell or tissue injury.

One of the main targets of attack by free radicals is the membrane lipids, resulting in the initiation of enzymatic lipid peroxidation. ${ }^{7}$ In higher plants, ROS react with $\alpha$-linolenic acid (ALA) in cell membranes, giving rise to phytoprostanes (PhytoPs). On the other hand, higher oxygen pressure has as a consequence the formation of an additional peroxidation product named phytofurans (PhytoFs), due to further oxidation after the primary cyclization of ALA. ${ }^{8}$

Salicylic acid (SA) is a plant hormone responsible for the control of diverse processes, namely, germination, cell growth, floral induction, absorption of ions, respiration, rate of 
Table 1. UHPLC/MS/MS Parameters for Quantification and Confirmation of Phytoprostanes and Phytofurans in Rice ${ }^{a}$

\begin{tabular}{|c|c|c|c|}
\hline $\operatorname{code}^{b}$ & compd & retention time $(\mathrm{min})$ & MRM transition $(m / z)$ \\
\hline \multicolumn{4}{|c|}{ Phytoprostanes } \\
\hline \multirow[t]{2}{*}{ PP1 } & 9- $\mathrm{F}_{1 \mathrm{t}}$-PhytoP $^{c}$ & 1.631 & $327.2 \rightarrow 273.1^{d}$ \\
\hline & & & $327.2 \rightarrow 171.0^{c}$ \\
\hline \multirow[t]{2}{*}{ PP2 } & ent-16- $\mathrm{F}_{1 t}-\mathrm{PhytoP}+$ ent-16-epi-16- $\mathrm{F}_{1 \mathrm{t}}$-PhytoP & 1.712 & $327.2 \rightarrow 283.2$ \\
\hline & & & $327.2 \rightarrow 225.1$ \\
\hline \multirow[t]{2}{*}{ PP2 } & ent-16-epi-16- $\mathrm{F}_{1 \mathrm{t}}-\mathrm{Phyto}^{c}$ & 1.583 & $327.1 \rightarrow 283.2^{e}$ \\
\hline & & & $327.1 \rightarrow 225.1^{d}$ \\
\hline \multirow[t]{2}{*}{ PP3 } & 9-epi-9- $\mathrm{F}_{1 \mathrm{t}}$-PhytoP & 1.785 & $327.2 \rightarrow 272.8$ \\
\hline & & & $327.2 \rightarrow 171.0$ \\
\hline \multirow[t]{2}{*}{ PP4 } & 9-epi-9- $\mathrm{D}_{1 \mathrm{t}}$-PhytoP & 2.022 & $325.2 \rightarrow 307.2$ \\
\hline & & & $325.2 \rightarrow 134.9$ \\
\hline \multirow[t]{2}{*}{ PP5 } & 9- $\mathrm{D}_{1 \mathrm{t}}-$ PhytoP & 1.791 & $325.2 \rightarrow 307.3$ \\
\hline & & & $325.2 \rightarrow 134.7$ \\
\hline \multirow[t]{2}{*}{ PP6 } & 16-B-BhytoP & 2.620 & $307.2 \rightarrow 223.2$ \\
\hline & & & $307.2 \rightarrow 235.1$ \\
\hline \multirow[t]{2}{*}{ PP7 } & 9- $\mathrm{L}_{1}-\mathrm{PhytoP}$ & 3.079 & $307.2 \rightarrow 185.1$ \\
\hline & & & $307.2 \rightarrow 196.7$ \\
\hline \multicolumn{4}{|c|}{ Phytofurans } \\
\hline \multirow[t]{2}{*}{ PF1 } & ent-16(RS)-9-epi-ST- $\Delta^{14}$-10-PhytoF & 1.501 & $343.9 \rightarrow 209.0$ \\
\hline & & & $343.9 \rightarrow 201.1$ \\
\hline \multirow[t]{2}{*}{ PF2 } & ent-9(RS)-12-epi-ST- $\Delta^{10}-13$-PhytoF & 0.906 & $344.0 \rightarrow 300.0$ \\
\hline & & & $344.0 \rightarrow 255.9$ \\
\hline \multirow[t]{2}{*}{$\mathrm{PF} 3$} & ent-16(RS)-13-epi-ST- $\Delta^{14}$-9-PhytoF & 1.523 & $343.0 \rightarrow 171.1$ \\
\hline & & & $343.0 \rightarrow 97.2$ \\
\hline
\end{tabular}

${ }^{a}$ All measurements were performed in ESI negative-ion mode. ${ }^{b}$ For each biomarker, the confirmation transition is listed first and the quantification transition is listed second. ${ }^{c}$ Coeluting diasteroisomers quantified together ${ }^{d}$ Confirmation transition. ${ }^{e}$ Quantification transition.

transpiration, net photosynthesis, stomatal conductance, flowering, senescence, and response to abiotic stress. SA is essential in thermogenesis, as well as in resistance to diseases, while it induces changes in leaf anatomy and chloroplast ultrastructure. ${ }^{9,10}$ In addition, this signaling hormone induces hypersensitive response and the expression of pathogenesisrelated genes, as well as systemic resistance in plants, ${ }^{11}$ closely related to plant defense by regulating $\mathrm{ROS}\left(\mathrm{H}_{2} \mathrm{O}_{2}\right.$ and $\left.\mathrm{O}_{2}{ }^{--}\right)$ levels, as well as enzymatic (ascorbic acid peroxidase, superoxide dismutase, catalase, glutathione S-transferase) and nonenzymatic antioxidant systems. ${ }^{12,13}$ The information reported so far on the physiological role of SA implies that it could also contribute to the plant's resistance against stressing factors by improving mechanical barriers. ${ }^{14}$ On the other hand, SA induces the synthesis of phenylalanine ammonia lyase (PAL). The activation of this enzyme by SA seems to contribute to modulating PAL gene expression and activation. ${ }^{14}$ Application of SA for agronomical purposes increases the endogenous content of SA and the expression of genes codifying critical redox-regulating proteins ( $N P R 1$ and $P R$ ), responsible, for instance, for the regulation of expression of TOP2 gene, closely related to plant resistance against abiotic stress. ${ }^{15}$ However, the data available are intriguing regarding the effect of exogenous SA on resistance against biotic and abiotic stress in plants. ${ }^{16}$

With respect to the relationship between salicylic acid and PhytoPs/PhytoFs, although the biological functions of these oxylipins before their conversion to jasmonic acid are less understood, to date, their contribution to a number of biological activities has been described, including activation of diverse enzymes, regulation of defense genes, and accumulation of antimicrobial compounds in plants. ${ }^{17}$ The pathways in which PhytoPs and PhytoFs are involved are distinct from the responses induced by jasmonate. In this regard, recently it has been demonstrated that oxylipins are generated before the accumulation of SA, in response to the activation of MPK3 and MPK6 induced by the guard cell lipoxygenase LOX1. ${ }^{18}$

In light of the information available, this research seeks to deepen the current understanding of the interrelationship of environment (open field versus plastic cover), widely managed in the local area, and the application of salicylic acid with the qualitative and quantitative presence of new and powerful markers of abiotic stress (PhytoPs and PhytoFs) in higher plants, by advanced chromatographic and spectrometric analyses in one well-characterized genotype (Oryza sativa L. subsp. japonica var. Yerua, here called Yerua) and six advanced lines $(\mathrm{R} / 03-5 \times$ desc/04-52-1-1, R/03-5 $\times$ desc/04-45-1-1, Amaroo $\times$ desc/08-1-1-1-2, R/03-5 $\times$ desc/04-27-3-1, R/03-5 $\times$ desc/14-1-1-1, and H489-5-1-2) belonging to the japonica rice type. These genetically diverse lines were obtained from the rice breeding program of the National University de la Plata (Argentina) and were implanted in the local area due to their agronomic features within a group of genotypes of the commercial type length and width.

\section{MATERIALS AND METHODS}

Chemical and Reagents. The standards for PhytoPs and PhytoFs were synthesized as previously described, ${ }^{8,19-23}$ and provided by the Institut des Biomolécules Max Mousseron (IBMM, Montpellier, France). n-Hexane was purchased from Panreac (Barcelona, Spain); butylated hydroxyanisole (BHA), bis-tris, and SA were obtained from Sigma-Aldrich (St. Louis, MO); and all LC/ MS-grade solvents used to complete the analytical tasks described in the present work were from J. T. Baker (Phillipsburg, NJ). Water was treated in a Milli-Q water purification system from Millipore (Bedford, MA). The solid-phase extraction (SPE) cartridges used 
(Strata X-AW, $100 \mathrm{mg} / 3 \mathrm{~mL}$ ) were from Phenomenex (Torrance, CA).

Plant Samples and Crop Management. The field trial was set up in the experimental field Julio Hirschhorn $\left(34^{\circ} 52^{\prime} \mathrm{S}, 57^{\circ} 57^{\prime} \mathrm{W}, 9.8\right.$ $\mathrm{m}$ altitude, La Plata, Buenos Aires, Argentina). This field experiment included the widespread variety in the producing area, Yerua PA ( Oryza sativa L. subsp. japonica var. Yerua, here called Yerua), and the six advanced lines R/03-5 $\times$ desc/04-52-1-1 (L1), R/03-5 $\times$ desc/0445-1-1 (L2), Amaroo $\times$ desc/08-1-1-1-2 (L3), R/03-5 $\times$ desc/04-273-1 (L4), R/03-5 × desc/14-1-1-1 (L5), and H489-5-1-2 (L6), all belonging to Oryza sativa ssp. japonica. The rice varieties were sourced by the Rice Breeding Program of the Agriculture and Forestry Sciences Faculty, National University de la Plata. The experimental design included randomized blocks with three repetitions. Dry-land seeding was done manually at a rate of 350 seeds $\cdot \mathrm{m}^{-2}$ in $0.20 \mathrm{~m}$ lines within plots of $5 \mathrm{~m}^{2}$. The assay was conducted by applying flood irrigation for 30 days after emergence. Weeds were controlled with bispiribac sodium. Three experimental conditions were included in the assay; no SA application (SA0, control condition), application of 1 $\mathrm{mM}$ SA (SA1), and application of $15 \mathrm{mM} \mathrm{SA}$ (SA15). These treatments were sprayed 10 and 17 days after anthesis. The SA solutions were prepared in distilled water with $50 \mathrm{ppm}$ Tween-20 surfactant. The plots were sprayed in late afternoon hours, under wind conditions of less than $10 \mathrm{~km} \cdot \mathrm{h}^{-1}$.

Regarding environmental conditions, the arable area evaluated was exposed to two diverse growing conditions: one was covered with plastic of $100 \mu \mathrm{m}$ thickness between the second SA application and harvest (crop EP), and the other was grown in the open (crop E). Temperature values were recorded by an XR440 Pocket TM data logger (Pace Scientific Inc., Charlotte, NC) every 30 min during the ripening. Two temperature sensors (PT940, Pace Scientific Inc.) were located in the canopy, at the panicle height ( $0.90 \mathrm{~m}$ off the ground) in both EP and E crop systems.

Samples of each rice variety were collected and threshed manually at maturity according to standard industrial processes. The kernels were dried in an oven at $40{ }^{\circ} \mathrm{C}$ until constant (14.0\%) humidity. Paddy grain samples $(100 \mathrm{~g})$ were flaked to obtain brown rice that was ground to a fine powder by milling in a Cyclone mill and passing the powder through $0.4 \mathrm{~mm}$ mesh; afterward, samples were stored under refrigeration until analysis.

Extraction and UHPLC-ESI-QqQ-MS/MS Analysis of Rice Phytoprostanes and Phytofurans. To obtain the PhytoP and PhytoF extracts from rice flours, we used the methodology reported by Pinciroli et al. ${ }^{24}$ The extracts obtained were cleaned up by SPE as previously described. ${ }^{25}$ Quantification of the extracted plant oxylipins was achieved by use of freshly prepared curves of authentic standards.

Chromatographic resolution of the PhytoPs and PhytoFs previously extracted was done by applying the instrumentation and methodology described by Collado-Gonzalez et al. ${ }^{25}$ and DomínguezPerles et $\mathrm{al}^{26}$ Identification and quantification of the individual PhytoPs and PhytoFs was developed by applying multiple reaction monitoring (MRM) in negative mode and assigning quantification and confirmation MRM transitions for each analyte (Table 1).

Statistical Analysis. All extractions were performed in triplicate $(n=3)$ and results are presented as means \pm standard deviation (SD). Statistical analysis was completed by use of Statgraphics Centurion XVI statistical software (StatPoint Technologies Inc., Warranton, VA) by which one-way analysis of variance (ANOVA) and multiple-range test (Tukey's test) were performed. Significant differences were set up at $p<0.05, p<0.01$, and $p<0.001$.

\section{RESULTS AND DISCUSSION}

To evaluate the effect of environmental conditions and SA spraying on the stress level of plants of different rice genotypes upon the modification of concentration of PhytoPs and PhytoFs, a field trial was established in an experimental station in the province of Buenos Aires, in central-east Argentina, which included the genotypes Yerua, R/03-5 $\times$ desc/04-52-1-1 (L1), R/03-5 × desc/04-45-1-1 (L2), Amaroo $\times$ desc/08-1-1-
1-2 (L3), R/03-5 × desc/04-27-3-1 (L4), R/03-5 × desc/14-11-1 (L5), and H489-5-1-2 (L6), all belonging to Oryza sativa subsp. japonica. The average air temperature of the canopy, during ripening in the two environments (EP, covered with plastic, and $\mathrm{E}$, open field), were $21.8^{\circ} \mathrm{C}$ (range 9.4-44.0 ${ }^{\circ} \mathrm{C}$ ) and $20.3{ }^{\circ} \mathrm{C}$ (range $6.8-39.5{ }^{\circ} \mathrm{C}$ ), respectively. These ranges fit adequately with the requirement of the rice crop, since optimum temperatures for rice during ripening oscillate between 20 and $29{ }^{\circ} \mathrm{C}$. ${ }^{4}$ Thus, given the temperature conditions recorded during the development of the field trial, the crops showed normal growth.

Phytoprostane and Phytofuran Content in Diverse Rice Genotypes. With respect to PhytoPs, the concentration of total compounds in the genotypes studied evidenced a decrease in concentration of these compounds as follows: Yerua $\left[1713.2 \mathrm{ng} \cdot \mathrm{g}^{-1}\right.$ dry weight $\left.(\mathrm{dw})\right]>\mathrm{L1}\left(1453.2 \mathrm{ng} \cdot \mathrm{g}^{-1}\right.$ $\mathrm{dw})>\mathrm{L} 6\left(425.9 \mathrm{ng} \cdot \mathrm{g}^{-1} \mathrm{dw}\right)>\mathrm{L} 2\left(420.4 \mathrm{ng} \cdot \mathrm{g}^{-1} \mathrm{dw}\right)>\mathrm{L} 4$ $\left(368.0 \mathrm{ng} \cdot \mathrm{g}^{-1} \mathrm{dw}\right)>\mathrm{L} 5\left(257.6 \mathrm{ng} \cdot \mathrm{g}^{-1} \mathrm{dw}\right)>\mathrm{L} 3\left(180.2 \mathrm{ng} \cdot \mathrm{g}^{-1}\right.$ $\mathrm{dw})$.

These levels were inferior to those observed in different rice genotypes belonging to Oryza sativa subsp. indica, as they ranged between 509.3 and $309.2{\mathrm{ng} \cdot \mathrm{g}^{-1} \mathrm{dw} .}^{24}$ However, other authors have found modifications in the concentration of total PhytoPs according to the variety. In this regard, Barbosa et al., ${ }^{27}$ in a study including 24 species of macroalgae, found the highest values in the species Saccharina latissima and the lowest in Asparagopsis armata (13.8 and $0.1 \mathrm{ng} \cdot \mathrm{g}^{-1} \mathrm{dw}$, respectively). Additionally, when studying 11 diverse almond cultivars exposed to an array of hydric stress growing conditions, Carrasco-Del Amor et al. ${ }^{28}$ described maximum values in the cultivar 'Blanqueta' and minimum values in the cultivar 'Garriges', with values of 238.1 and $40.3 \mathrm{ng} \cdot \mathrm{g}^{-1}$, respectively. Finally, in 2017, Pinciroli et al. ${ }^{24}$ studied 14 genotypes of rice, stating the maximum level of PhytoPs in the japonica variety 'Itape', with values of 9.2, 32.9, and $67.1 \mathrm{ng} \cdot \mathrm{g}^{-1}$ for white grain, brown grain, and bran flours, respectively. In this work, upon profiling PhytoPs in rice flour from the seven varieties under study, independently of the environmental growing condition (open field or plastic cover) and salicylic acid treatment, the following decreasing average concentrations of individual PhytoPs were observed: ent-16- $\mathrm{F}_{1 \mathrm{t}}$-PhytoP + ent-16-epi-16$\mathrm{F}_{1 \mathrm{t}}$-PhytoP (PP2, $\left.333.8 \mathrm{ng} \cdot \mathrm{g}^{-1} \mathrm{dw}\right)>9-\mathrm{F}_{1 \mathrm{t}}$-PhytoP (PP1, 172.5 $\left.\mathrm{ng} \cdot \mathrm{g}^{-1} \mathrm{dw}\right)>9-$ epi-9-F $1 \mathrm{t}^{-}$PhytoP (PP3, $\left.164.0 \mathrm{ng} \cdot \mathrm{g}^{-1} \mathrm{dw}\right)>9$ -

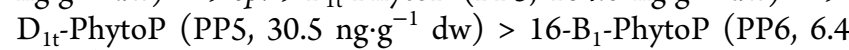
$\left.\mathrm{ng} \cdot \mathrm{g}^{-1} \mathrm{dw}\right)>9-\mathrm{L}_{1}-$ PhytoP $\left(\mathrm{PP} 7,4.5 \mathrm{ng} \cdot \mathrm{g}^{-1} \mathrm{dw}\right)>$ 9-epi-9-- $\mathrm{D}_{1 \mathrm{t}^{-}}$

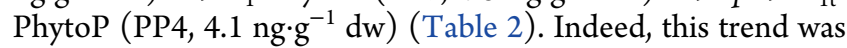
also observed when the isolated effects of salicylic acid treatments on these plant oxylipins were evaluated (Figure 1).

When the abundance of separate PhytoPs was compared in the variety Yerua and the six advanced genotypes, the overall analysis, developed independently for the environmental and salicylic acid treatment effects, showed that, on average, Yerua displayed the highest concentrations of PP1-PP7 (353.3, 803.8, 445.1, 6.3, 75.3, 17.7, and $11.8 \mathrm{ng} \cdot \mathrm{g}^{-1} \mathrm{dw}$, respectively). These values surpassed the level of the variety exhibiting the second higher concentration, the advanced genotype L1, from $7.9 \%$ to $46.3 \%$, and the advanced genotypes L2-L6, which remained at similar lower levels, from $46.3 \%$ to $86.2 \%$ (Table 2).

Comparison of the results obtained with other plant foods suggests that $\mathrm{F}_{1}-$ PhytoPs series is also the most abundant in dry melon leaves of cultivars Sweet Ball and Early Spring $\left(2740.0\right.$ and $2340.0 \mathrm{ng} \cdot \mathrm{g}^{-1}$, respectively $){ }^{29}$ in aged wine and 


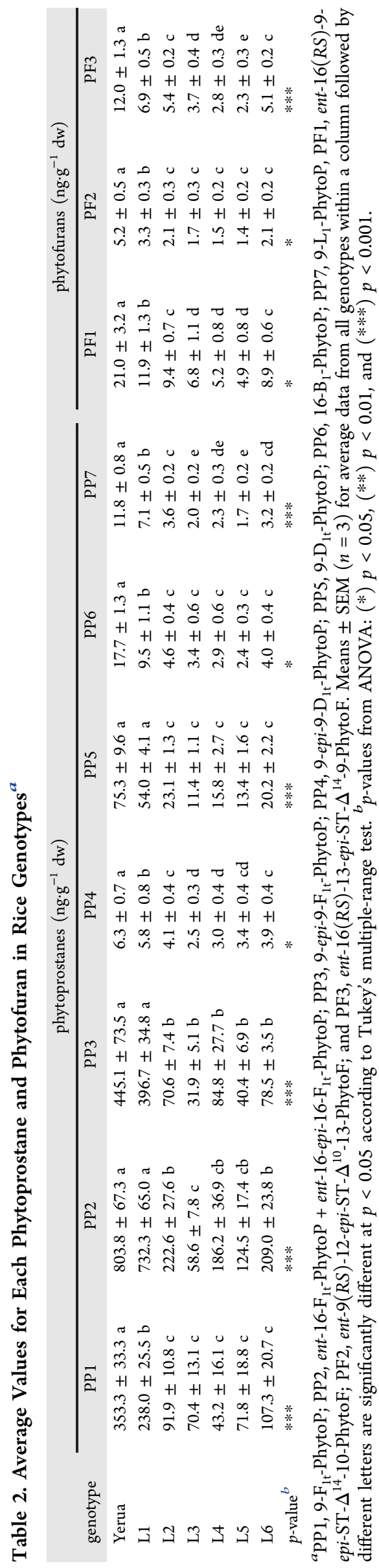

grape musts (210.7 and $18.0 \mathrm{ng} \cdot \mathrm{mL}^{-1}$ on average, respectively), ${ }^{30}$ in olive oil $(8.1 \mathrm{ng} / \mathrm{mL}$ on average $),{ }^{31}$ in almonds (90.6 $\mathrm{ng} \cdot \mathrm{g}^{-1}$ on average), ${ }^{28}$ and in macroalgae (2.7 $\mathrm{ng} \cdot \mathrm{g}^{-1}$, on average $){ }^{27}$

In addition to PhytoPs, evaluation of the array of rice grains on the occurrence of plant oxylipins was also focused on PhytoFs. The average concentrations of individual PhytoFs in the separate genotypes of rice showed the following decreasing levels: ent-16(RS)-9-epi-ST- $\Delta^{14}-10-$ PhytoF (PF1, $9.7 \mathrm{ng} \cdot \mathrm{g}^{-1}$ $\mathrm{dw})>$ ent-16(RS)-13-epi-ST- $\Delta^{14}$-9-PhytoF (PF3, $5.5 \mathrm{ng} \cdot \mathrm{g}^{-1}$ $\mathrm{dw})>$ ent-9(RS)-12-epi-ST- $\Delta^{10}-13$-PhytoF (PF2, $2.5 \mathrm{ng} \cdot \mathrm{g}^{-1}$ $\mathrm{dw})$ (Figure 2). These values matched those reported by Pinciroli et al. ${ }^{24}$ in an array of diverse rice flours obtained from varieties belonging to Oryza sativa subsp. japonica and indica. Again, when concentrations of PhytoFs were compared in the range of rice grains under study, it was noticed that Yerua featured the highest content of PF1, PF2, and PF3 (21.0, 5.2, and $12.0 \mathrm{ng} \cdot \mathrm{g}^{-1} \mathrm{dw}$, respectively), while the advanced genotypes L1, L2, and L6 presented lower concentrations $\left(10.1,2.5\right.$, and $5.8 \mathrm{ng} \cdot \mathrm{g}^{-1} \mathrm{dw}$, respectively). The remaining genotypes L3, L4, and L5 were found in similar lower levels with average concentrations of 5.6, 1.5 , and $2.9 \mathrm{ng} \cdot \mathrm{g}^{-1} \mathrm{dw}$, respectively (Table 2 ).

In all cases, significant differences between genotypes were revealed (Table 2). These results are fairly consistent with previous reports available in the literature indicating genetic varietal differences in response to high critical temperatures, ${ }^{4,32}$ according to their ability to regulate redox homeostasis in cells.

Pinciroli et al., ${ }^{24}$ upon studying 14 diverse genotypes of rice, discerned a lower concentration of total PhytoFs, on average $0.7,4.4$, and $10.7 \mathrm{ng} \cdot \mathrm{g}^{-1} \mathrm{dw}$ in white grain, brown grain, and bran flours. Furthermore, PhytoFs have also been studied in a few additional plant matrices. In this regard, Cuyamendous et al. ${ }^{33}$ reported the occurrence of these compounds in nuts and vegetable oils ranging between 0.30 and $9.00 \mathrm{ng} \cdot \mathrm{g}^{-1}$. In the same way, Yonny et al. ${ }^{29}$ described their occurrence in leaves of melon, found at $2355.0 \mathrm{ng} \cdot \mathrm{g}^{-1} \mathrm{dw}$.

Environmental Effects on Levels of Phytoprostanes and Phytofurans in Rice. The average temperatures during ripening were 20.3 and $21.8{ }^{\circ} \mathrm{C}$ in the $\mathrm{E}$ and $\mathrm{EP}$ systems, respectively, while the results revealed that plastic cover provided less stressful growing conditions for the genotypes assessed. Rice is a tropical or subtropical species that, in the experimental procedure described in the present work, was grown under suboptimal conditions in terms of thermic supply. The warm environment provided by the plastic cover was found to be favorable for the development of all genotypes. Heat stress entails a myriad of cellular events in plants when temperature rises beyond a threshold level during a lapse of time that causes irreversible damage to plants. ${ }^{34,35}$ In this regard, previous studies demonstrated that optimal air temperature for rice ripening, in plants belonging to japonica varieties, ranges from 20 to $25{ }^{\circ} \mathrm{C}$, while higher or lower temperatures may reduce significantly grain yield. ${ }^{3,36}$ Hence, damages by high temperatures may turn out to be severe, depending on the duration. For instance, a period of 20 days with temperatures above $27^{\circ} \mathrm{C}$, during ripening, seems to be enough to decrease grain production, grain weight, and protein content as well as to augment chalkiness. ${ }^{37}$ On the other hand, 15 days at $30{ }^{\circ} \mathrm{C}$ has been demonstrated to reduce significantly rice yield and appearance quality, while change grain shape. ${ }^{38,39}$ In addition, even higher temperatures $\left(35^{\circ} \mathrm{C}\right.$ for 5 days) cause damage in the phenological phases and infertility 

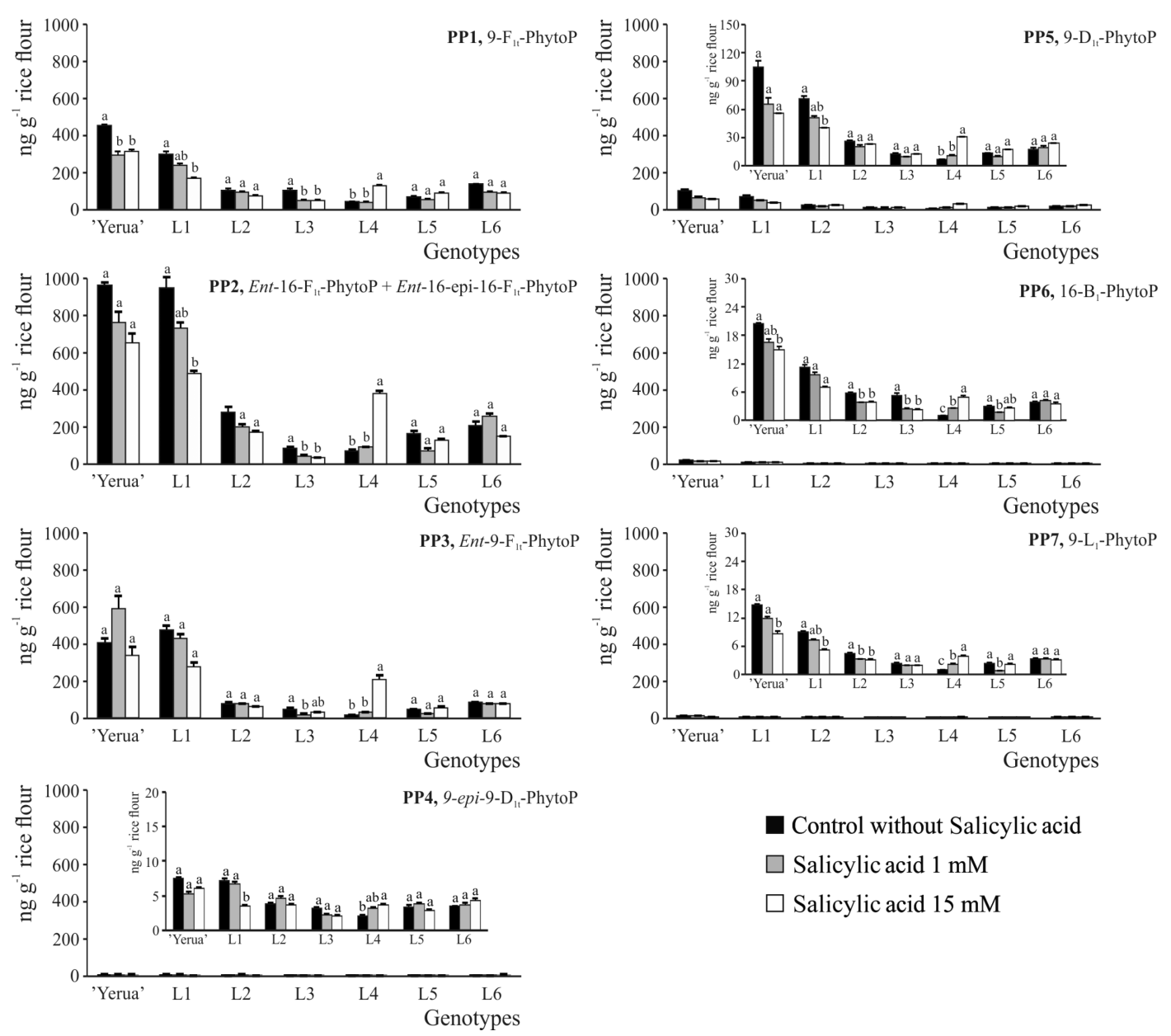

$\square$ Control without Salicylic acid
$\square$ Salicylic acid $1 \mathrm{mM}$
$\square$ Salicylic acid $15 \mathrm{mM}$

Figure 1. Comparison between different salicylic acid supplementation levels in the seven varieties of rice, Yerua and L1-L6, for PhytoPs PP1-PP7. Different lowercase letters indicate significant differences between SA supplementation for the same genotype at $p<0.05$, according to ANOVA and the multiple-range test of Tukey.

of the spikelets in rice plants. ${ }^{36}$ In our study, high temperatures were recorded for 8 and $6 \mathrm{~h}$ in plastic cover (EP) and open field (E) environments, respectively (Supporting Information). These conditions caused no harmful effect, contrary to what was expected accordingly to the information available in the literature.

When evaluating the differential response of rice genotypes to the environment in crops set up under EP or E conditions, concerning the level of individual PhytoPs and PhytoFs, it was found that, overall, EP growing rice had a significantly reduced $(p<0.05)$ concentration of most of the stress biomarkers analyzed (by $3.9 \%$ on average). This decrease was statistically significant for PP1 (from 153.5 to $133.9 \mathrm{ng} \cdot \mathrm{g}^{-1} \mathrm{dw}$, a $12.7 \%$ reduction) and PF2 (from 2.6 to $2.3 \mathrm{ng} \cdot \mathrm{g}^{-1} \mathrm{dw}$, a $10.4 \%$ reduction) (Table 3 ). In this regard, the reduction in photosynthetically active radiation (PAR) in EP was approximately $76 \%$ with respect to $\mathrm{E}$ (data not shown). It is possible that the electron transport chain was not saturated with light; therefore, a lower amount of ROS was produced, and consequently a lower content of plant oxylipins. This result matches the behavior of melatonin in most pepper cultivars studied. ${ }^{40}$ In addition, in work carried out on melon leaves, the compound that showed the most significant changes of concentration as a consequence of different environments was $9-\mathrm{F}_{1}$-PhytoP. In this study, the plastic cover raised temperatures to values between 35 and $45{ }^{\circ} \mathrm{C}$, inducing severe heat stress and a subsequent increase in PhytoP and PhytoF concentrations. $^{29}$ Possibly the increase in ROS due to the growing temperatures caused greater lipid peroxidation of ALA, and thus a proportional change in the level of cyclic metabolites.

Effect of Supplementation with Salicylic Acid on Phytoprostane and Phytofuran Levels in Rice. When we analyzed the impact of treatment with two levels of salicylic acid (1 and $15 \mathrm{mM}$, labeled SA1 and SA15, respectively) of rice crops of variety Yerua and six advanced genotypes (lines L1-L6) on the content of total PhytoPs and PhytoFs of rice grains, significant effects were identified concerning almost all PhytoPs and PhytoFs. In general, a decreasing concentration of biomarkers was observed due to exogenous application of SA (SA1 and SA15) relatively to the control (SA0). The concentrations of PP3 and PP4 did not change significantly due to SA supplementation (Table 3), while those of all other PhytoPs and PhytoFs were lowered significantly after treatment with SA at both dosages (PP1 from 174.7 to131.5, PP2 from 396.0 to291.5, PP5 from 35.8 to 28.9 , PP6 from 7.3 to 5.7, PP7 from 5.3 to 4.0, PF1 from 12.0 to 8.8, PF2 from 3.0 to 2.3, and PF3 from 6.8 to $4.7 \mathrm{ng} \cdot \mathrm{g}^{-1} \mathrm{dw}$ ), without presenting differences from one to another (Table 3 ). This result suggests that, even at low doses, the exogenous application of SA (with hormonal functions in the frame of plant physiology) features strong radical scavenging capacity. Indeed, SA plays a crucial 
Control without Salicylic acid

$\square$ Salicylic acid $1 \mathrm{mM}$

$\square$ Salicylic acid $15 \mathrm{mM}$
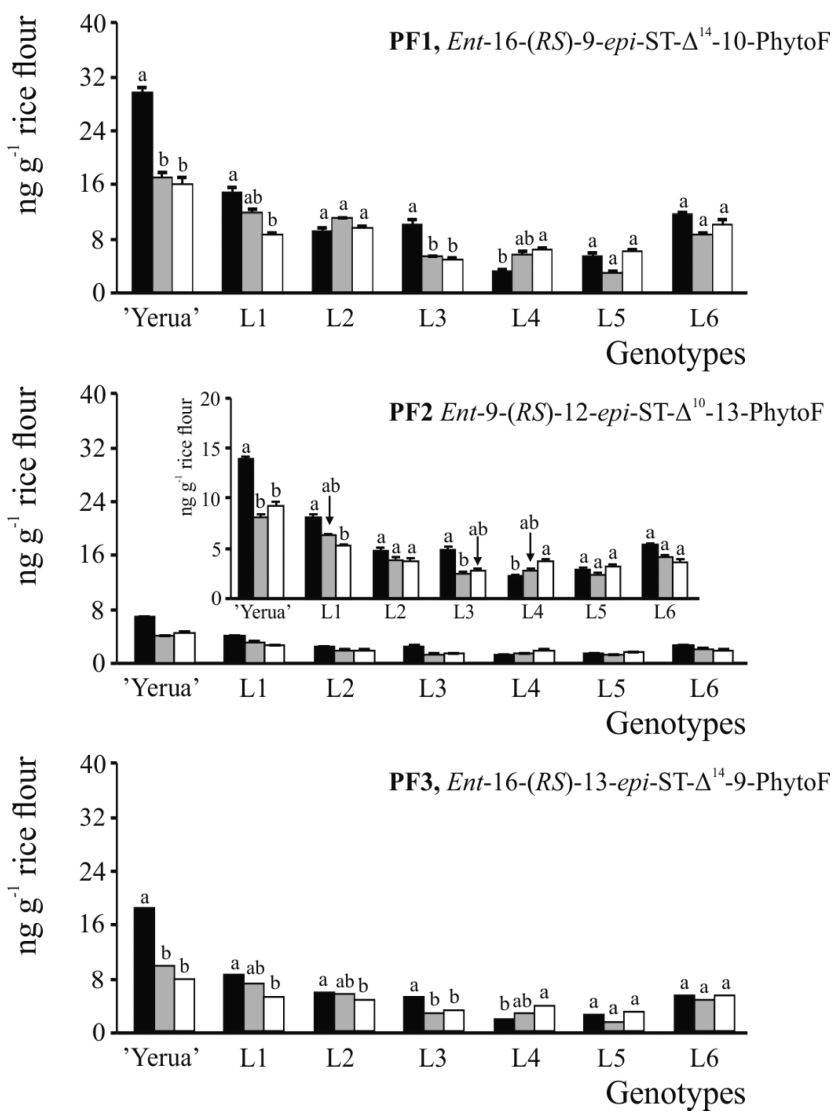

Figure 2. Comparison between different salicylic acid supplementation levels in the seven varieties of rice, Yerua and L1-L6, for PhytoFs PF1, PF2, and PF3. Different lowercase letters indicate significant differences between SA supplementation for the same genotype at $p<$ 0.05 , according to ANOVA and the multiple-range test of Tukey.

role in the control of cellular redox homeostasis in plants. ${ }^{6,12,13}$ Regarding this, Clarke et al. ${ }^{40}$ demonstrated that SA-dependent signaling plays a role in the maintenance of basal thermotolerance. Additionally, both authors observed lower electrolyte leakage after heat stress, together with the induction of pathogenesis-related proteins in 3-week-old Arabidopsis leaves with SA applications. This fact was further supported by studies conducted on Cicer arietinum plants, which revealed that the application of SA significantly reduced cell membrane lesions induced by heat stress. ${ }^{9}$

Although heat stress was not extreme in the experimental work developed, the decreased level of PhytoPs and PhytoFs upon application of SA suggests that this could improve the adaptation of rice plants to augmented levels of ROS and leakage of electrolytes generated during temperature increase or excesses of radiation. This may allow a modular redox balance and thus protect plants from oxidative stress. Hence, according to Hayat et al., 9 SA effectively alleviated the toxic effects generated in plants as a consequence of exposure to abiotic stress factors.

The concentrations of PP1, PP2, PP3, PP5, and PF3 responded differentially to growing conditions, being revealed as compounds with significant sensitivity to the interaction

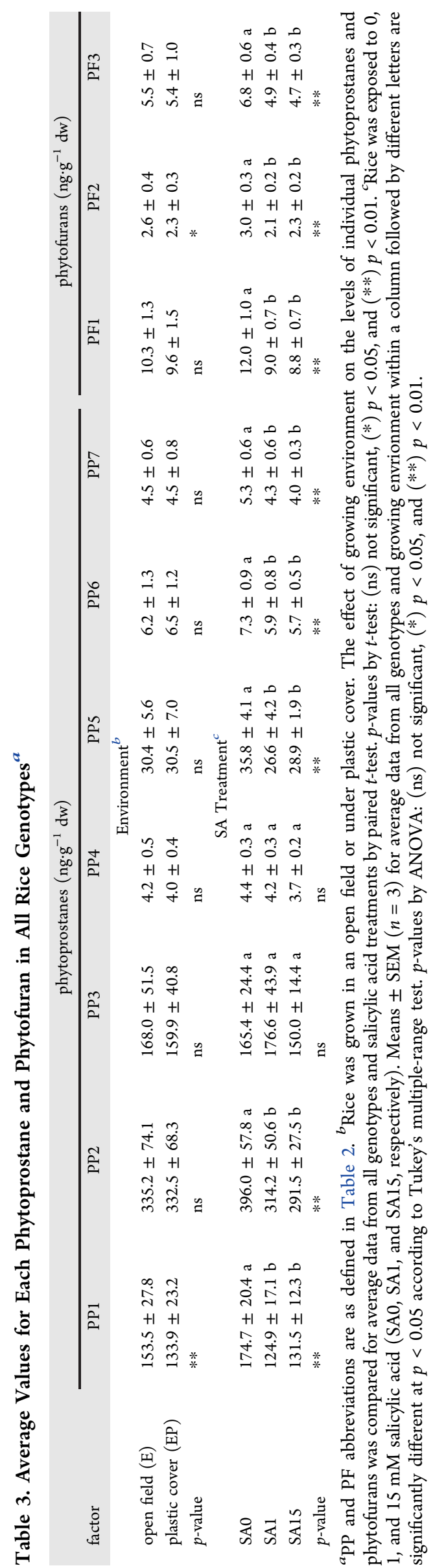


Table 4. $p$-Values Corresponding to Interactions between Genotype, Growing Environment, and Salicylic Acid Treatments Evaluated in This Study ${ }^{a}$

\begin{tabular}{|c|c|c|c|c|c|c|c|c|c|c|}
\hline \multirow[b]{2}{*}{ interacting factors } & \multicolumn{7}{|c|}{ phytoprostanes } & \multicolumn{3}{|c|}{ phytofurans } \\
\hline & PP1 & PP2 & PP3 & PP4 & PP5 & PP6 & PP7 & PF1 & PF2 & PF3 \\
\hline environment $\times$ SA & $*$ & * & $* *$ & ns & $* *$ & ns & ns & ns & ns & $* * *$ \\
\hline environment $\times$ genotype & $* * *$ & ns & ns & $*$ & ns & $*$ & ns & $*$ & $*$ & ns \\
\hline$S A \times$ genotype & $* * *$ & $* * *$ & $* * *$ & $* * *$ & $* * *$ & $* * *$ & $* * *$ & $* * *$ & $* * *$ & $* * *$ \\
\hline environment $\times \mathrm{SA} \times$ genotype & ns & $* *$ & $* * *$ & $\mathrm{~ns}$ & $* * *$ & ns & $* *$ & $*$ & ns & $* * *$ \\
\hline
\end{tabular}

environment $\times$ SA (Table 4). Hence, we noted a decrease in concentration of PP1, PP2, PP3, PP5, and PF3 upon interaction between the application of both 1 and $15 \mathrm{mM}$ SA and the growing environments (EP and E). In addition, interactions between environment and genotype were identified for PP1, PP4, PP6, PF1, and PF2 (Table 4). However, the most significant interaction corresponded to SA and genotype, which affected all genotypes evaluated with a degree of statistical significance of $p<0.001$. This result encourages to analyze the differeces concerning the level of total and individual PhytoPs and PhytoFs upon application of different concentrations of SA (SA1 and SA15).

In the findings reported so far, when we analyzed the evolution of total PhytoPs and PhytoFs after different applications of SA, we found that total PhytoP concentrations, calculated as the average of all genotypes, were 772.9 (SA0),

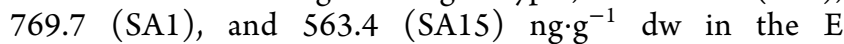
environment (open growth) and 752.2 (SA0), 543.8 (SA1), and 650.7 (SA15) $\mathrm{ng} \cdot \mathrm{g}^{-1} \mathrm{dw}$ in the EP environment (plastic cover). On the other hand, regarding total PhytoFs, the concentrations observed were 21.0 (SA0), 17.0 (SA1), and

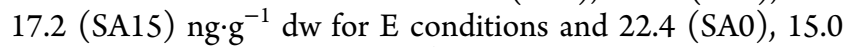
(SA1), and 14.4 (SA15) ng.g ${ }^{-1} \mathrm{dw}$ for EP conditions. These results suggest more significant interactions between the application of salicylic acid and the growing environment (E and EP) for the application of 1 and $15 \mathrm{mM}$ SA for PhytoPs and PhytoFs, respectively, with decreases of $29.3 \%$ and $16.3 \%$ of the total concentration, respectively.

The impact of hormones can be beneficial or toxic, depending on the concentration in which they are present in plant tissues. According to Janda et al., ${ }^{15}$ the effect of SA on heat tolerance in mustard plants depends on the concentration. Thus, in this work, SA exhibited a protective effect only at low concentrations $(0.01-0.1 \mathrm{mM})$. In addition, Clarke et al. ${ }^{40}$ showed that pretreatment with SA at doses of 0.5 or $1.0 \mathrm{mM}$ promotes basal thermotolerance in Arabidopsis plants.

Differential Response of Rice Genotypes to Treatments. Figures 1 and 2 show the modification of concentrations of individual PhytoPs and PhytoFs through increasing concentration of SA applied to the crops. In general, the behavior was similar for all the compounds studied: supplementation with SA almost invariably induced a reduction in individual PhytoP and PhytoF concentrations, with the exception of line L4, which showed higher levels of PhytoPs and PhytoFs in plants treated with $15 \mathrm{mM}$ SA (Figures 1 and 2).

In parallel, the environment $\times \mathrm{SA} \times$ genotype interaction was also analyzed (Table 4). Upon sorting all possible combinations from the lowest to the highest concentration of PhytoPs and PhytoFs, the lowest concentration values corresponded to the advanced lines L3, L4, and L5 for all SA doses assayed in the two environments.
The divergence between genotypes in their response to stress can be attributed to the efficiency in neutralizing ROS. In this frame, the capacity of plants to overcome such stress is closely dependent on their capacity to trigger the molecular mechanisms that contribute to fine-tune the plant metabolism properly. $^{32}$

Nowadays, there is a broad body of literature on the effect of abiotic stress on secondary metabolites, including PhytoPs. Collado-González et al. $^{41}$ studied the content of PhytoPs present in oil from Olea europaea L., cv. Cornicabra, and observed that their content increased in plants grown in deficit irrigation. The qualitative and quantitative differences in the content of PhytoPs indicate critical consequences of the cultivar, as well as the manufacturing and storage settings involved in autoxidation reactions. ${ }^{31}$ These authors studied the concentration of PhytoPs in olive pulp harvested from plants grown with and without water stress. The results obtained indicated that the content of PP1 and PP3 increases in the pulp of olives subjected to water stress. The total content of PhytoPs varied in the five cultivars studied. ${ }^{42}$ Carrasco-Del Amor et al. $^{28}$ studied 11 almond cultivars in an agricultural system (conventional or ecological) and in rain-fed and irrigation conditions. Almonds from trees fed by rain featured lower PhytoP concentrations relative to those obtained under irrigation. Yonny et al. ${ }^{29}$ assessed leaves of melon plants for the concentration of PhytoPs and PhytoFs under heat stress conditions, evidencing the key influence of stress that entailed an increase relative to samples not subjected to stress, although they did not observe differences between varieties in the behavior.

Hence, according to previous reports in the literature jointly with the results obtained in the present work, it follows that there are qualitative and quantitative differences in the content of PhytoPs that indicates the influence of the variety, technology, and/or storage conditions of plant matrices. Hence, the conversion of polyunsaturated fatty acids into autoxidative products in vivo allows the generation of a much wider range of metabolites that are also rich in biochemistry and versatile. ${ }^{43}$ Given this complexity, further research is required to shed some light on the factors and mechanisms involved in the production of PhytoPs and how diverse types of stress (biotic and abiotic) can affect these pathways. ${ }^{25}$

We empahsize the critical relevance of agronomical practices and industrial processes that are closely related to the level of PhytoPs in plant foods. Hence, to gain further understanding of these processes and the actual effect on the levels of plant oxylipins would provide useful information to the successful functionalization of plant products by augmenting the concentrations of these compounds. ${ }^{44}$ Interestingly, upon this work, it was revealed that the concentration of these compounds in fresh plant material was more than 2 orders of magnitude higher than that of $\mathrm{F}_{2}$-isoprostanes $\left(\mathrm{F}_{2}\right.$-IsoP), 
derived from arachidonic acid, in mammalian tissues. Regarding this, Karg et al. ${ }^{43}$ demonstrated that $\mathrm{F}_{1}$-PhytoPs are bioaccessible and bioavailable. Closely linked with this and with respect to their functionality, recently possible functions as anti-inflammatory and apoptosis-inducing compounds, by acting as cyclopentenone prostaglandin-like molecules, have been suggested. ${ }^{43}$ It is expected that, in the next few years, these esterified derivatives could be accurately identified, resorting to spectrometric tools, and synthesized. Gaining this knowledge and reagents would help to assess their occurrence in cells and tissues after oral administration and to obtain further insight in their bioactive capacities upon a wide range of cellular models. ${ }^{43}$

The possibility of having genetic materials more tolerant to heat stress allows the expansion of areas suitable for rice cultivation or adapted to climate changes that are expected in the near future, without changes in production costs and ensuring sustainability and environment protection.

In summary, the data retrieved through the present work showed that growth under plastic cover and spray application of SA have direct impacts on the level of oxidative stress of rice plants, as indicated the decreased concentration of most of these newly established stress biomarkers $\left[9-\mathrm{F}_{1 \mathrm{t}}-\mathrm{PhytoP}\right.$ (PP1), ent-16- $\mathrm{F}_{1 \mathrm{t}}-\mathrm{PhytoP}+$ ent-16-epi-16- $\mathrm{F}_{1 \mathrm{t}}$-PhytoP (PP2), 9-epi-9$\mathrm{F}_{1 \mathrm{t}}$-PhytoP (PP3), 9-epi-9- $\mathrm{D}_{1 \mathrm{t}}$-PhytoP (PP4), 9- $\mathrm{D}_{1 \mathrm{t}}$-PhytoP

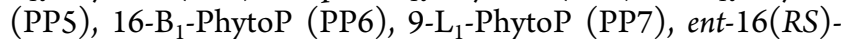
9-epi-ST- $\Delta^{14}-10$-PhytoF (PF1), ent-9(RS)-12-epi-ST- $\Delta^{10}-13$ PhytoF (PF2), and ent-16(RS)-13-epi-ST- $\Delta^{14}-9-$ PhytoF (PF3)]. In this regard, according to the evolution of the levels of these markers of abiotic stress, the reductions ranged between $22.9 \%$ and $79.9 \%$. The intensity of the decrease seems to depend on the sensitivity of separate genotypes to the salicylic acid sprayed, as well as to the efficiency of the agronomic practices implemented. This information on the behavior of PhytoPs and PhytoFs under differential environmental conditions and exogenous application of antioxidants will contribute to understanding the mechanisms of rice plants against abiotic stress, as well as the extent to which PhytoPs and PhytoFs contribute to defense and signaling activities. In this regard, the variations found in the level of plant oxylipins for rice plants grown under different conditions suggest that these metabolites are generated in situations of stress conditioned by the presence of ROS and respond to the effects of plant hormones. This information would allow us to understand more clearly its functions in plant metabolism. Supplementation with SA could be a promising management practice in warmer years, which will be more and more frequent in the coming years due to climate change, mitigating the damaging effects of heat stress. In this sense, the information obtained will help to understand the physiological tools of higher plants to stand protected against external aggressions, which is essential to obtaining, through bioengineering approaches, more resistant varieties upon breeding. Such varieties would increase arable field suitable for cultivation, production, and overall nutritional and physical quality. Simultaneously, new knowledge would contribute to maintaining production costs and guarantee the sustainability of resources and environment.

\section{ASSOCIATED CONTENT}

\section{(S) Supporting Information}

The Supporting Information is available free of charge on the ACS Publications website at DOI: 10.1021/acs.jafc.8b04975.
One figure showing air temperature during ripening under $\mathrm{E}$ and $\mathrm{EP}$ conditions (PDF)

\section{AUTHOR INFORMATION}

Corresponding Authors

*(R.D.-P.) E-mail rdperles@cebas.csic.com; tel +34968396200 , ext 6247.

*(A.G.-I.) E-mail angelgil@cebas.csic.com; tel +34968396200, ext 6363.

ORCID $\odot$

R. Domínguez-Perles: 0000-0001-6232-712X

C. Oger: 0000-0002-5177-5792

Funding

This work was partially funded by the Fundación Séneca de la Región de Murcia Grupo de Excelencia 19900/GERM/15. This work is included in the framework of the collaboration between the Spanish Research Council (CEBAS-CSIC) and CNRS-University of Montpellier by Projets Internationaux de Cooperation Scientifique (PICS-2015-261141). M.P.was sponsored by a predoctoral fellowship of the Asociacion Universitaria Iberoamericana de Postgrado (RR 631-2016) of the University of Murcia (Spain). R.D.-P. was sponsored by a postdoctoral contract (Juan de la Cierva de Incorporación ICJI-2015-25373) from the Ministry of Economy, Industry and Competitiveness of Spain. We thank the English expert reviewer (Dr. David James Walker) for revision of the English style and grammar.

\section{Notes}

The authors declare no competing financial interest.

\section{ABBREVIATIONS}

BHA, butylated hydroxyanisole; PhytoP, phytoprostane; PhytoF, phytofuran; ROS, reactive oxygen species; SA, salicylic acid; SPE, solid-phase extraction; UHPLC-ESI-QqQ-MS/MS, ultra-high-performance liquid chromatography coupled to electrospray ionization and triple quadrupole mass spectrometry

\section{REFERENCES}

(1) Arguissain, G. G., Ecofisiología del Cultivo de Arroz. In El Arroz, su cultivo $y$ sustentabilidad en Entre Rios; Benavidez, R., Ed.; Universidad Nacional del Litoral y Universidad Nacional de Entre Ríos: 2006; Vol. 1, pp 75-89.

(2) Yamakawa, H.; Hakata, M. Atlas of rice grain filling-related metabolism under high temperature: joint analysis of metabolome and transcriptome demonstrated inhibition of starch accumulation and induction of amino acid accumulation. Plant Cell Physiol. 2010, 51 (5), 795-809.

(3) Yamakawa, H.; Hirose, T.; Kuroda, M.; Yamaguchi, T. Comprehensive expression profiling of rice grain filling-related genes under high temperature using DNA microarray. Plant Physiol. 2007, 144 (1), 258-77.

(4) De Datta, S. K. Principles and practices of rice production; John Wiley \& Sons: 1981.

(5) Wu, Y.-C.; Chang, S.-J.; Lur, H.-S. Effects of field high temperature on grain yield and quality of a subtropical type japonica rice-Pon-Lai rice. Plant Prod. Sci. 2016, 19 (1), 145-153.

(6) Holuigue, L.; Salinas, P.; Blanco, F.; Garretón, V., Salicylic acid and reactive oxygen species in the activation of stress defense genes. In Salicylic Acid - A Plant Hormone; Hayat, S., Ahmad, A., Eds. Springer: 2007; Chapt. 8, pp 197-246; DOI: 10.1007/1-4020-51840. 
(7) Anderson, M. D.; Chen, Z.; Klessig, D. F. Possible involvement of lipid peroxidation in salicylic acid-mediated induction of PR-1 gene expression. Phytochemistry 1998, 47 (4), 555-566.

(8) Cuyamendous, C.; Leung, K. S.; Durand, T.; Lee, J. C.; Oger, C.; Galano, J. M. Synthesis and discovery of phytofurans: metabolites of alpha-linolenic acid peroxidation. Chem. Commun. (Cambridge, U. K.) 2015, 51 (86), 15696-9.

(9) Hayat, Q.; Hayat, S.; Irfan, M.; Ahmad, A. Effect of exogenous salicylic acid under changing environment: A review. Environ. Exp. Bot. 2010, 68 (1), 14-25.

(10) Rivas-San Vicente, M.; Plasencia, J. Salicylic acid beyond defence: its role in plant growth and development. J. Exp. Bot. 2011, 62 (10), 3321-38.

(11) Loake, G.; Grant, M. Salicylic acid in plant defence-the players and protagonists. Curr. Opin. Plant Biol. 2007, 10 (5), 466472.

(12) Smith, J. L.; De Moraes, C. M.; Mescher, M. C. Jasmonate- and salicylate-mediated plant defense responses to insect herbivores, pathogens and parasitic plants. Pest Manage. Sci. 2009, 65 (5), 497503.

(13) Maghsoudi, K.; Arvin, M. J. Response of seed germination and seedling growth of wheat (Triticum aestivum L.) cultivars to interactive effect of salinity and salicylic acid. J. Plant Ecophysiology 2010, 2, 91-96.

(14) Yang, C.; Hu, L. Y.; Ali, B.; Islam, F.; Bai, Q. J.; Yun, X. P.; Yoneyama, K.; Zhou, W. J. Seed treatment with salicylic acid invokes defence mechanism of Helianthus annuus against Orobanche cumana. Ann. Appl. Biol. 2016, 169 (3), 408-422.

(15) Janda, T.; Horváth, E.; Szalai, G.; Páldi, E., Chapter 5. Role of salicylic acid in the induction of abiotic stress tolerance. In Salicylic Acid - A Plant Hormone; Springer: 2007; Chapt. 5, pp 91-150; DOI: $10.1007 / 1-4020-5184-0$.

(16) Gill, R. A.; Zhang, N.; Ali, B.; Farooq, M. A.; Xu, J.; Gill, M. B.; Mao, B.; Zhou, W. Role of exogenous salicylic acid in regulating physio-morphic and molecular changes under chromium toxicity in black- and yellow- seeded Brassica napus L. Environ. Sci. Pollut. Res. 2016, 23 (20), 20483-20496.

(17) Thoma, I.; Loeffler, C.; Sinha, A. K.; Gupta, M.; Krischke, M.; Steffan, B.; Roitsch, T.; Mueller, M. J. Cyclopentenone isoprostanes induced by reactive oxygen species trigger defense gene activation and phytoalexin accumulation in plants. Plant J. 2003, 34 (3), 363-75.

(18) Montillet, J.-L.; Leonhardt, N.; Mondy, S.; Tranchimand, S.; Rumeau, D.; Boudsocq, M.; Garcia, A. V.; Douki, T.; Bigeard, J.; Laurière, C.; Chevalier, A.; Castresana, C.; Hirt, H. An abscisic acidindependent oxylipin pathway controls stomatal closure and immune defense in Arabidopsis. PLoS Biol. 2013, 11 (3), e1001513e1001513.

(19) Cuyamendous, C.; Leung, K. S.; Bultel-Poncé, V.; Guy, A.; Durand, T.; Galano, J. M.; Lee, J. C. Y.; Oger, C. Total synthesis and in vivo quantitation of phytofurans derived from $\alpha$-linolenic acid. Eur. J. Org. Chem. 2017, 2017, 2486-2490.

(20) El Fangour, S.; Guy, A.; Despres, V.; Vidal, J. P.; Rossi, J. C.; Durand, T. Total synthesis of the eight diastereomers of the syn-antisyn phytoprostanes F1 types I and II. J. Org. Chem. 2004, 69 (7), 2498-503.

(21) El Fangour, S.; Guy, A.; Vidal, J. P.; Rossi, J. C.; Durand, T. A flexible synthesis of the phytoprostanes B1 type I and II. J. Org. Chem. 2005, 70 (3), 989-97.

(22) Guy, A.; Flanagan, S.; Durand, T.; Oger, C.; Galano, J. M. Facile synthesis of cyclopentenone B1- and L1-type phytoprostanes. Front. Chem. 2015, 3, 41.

(23) Pinot, E.; Guy, A.; Fournial, A.; Balas, L.; Rossi, J. C.; Durand, T. Total Synthesis of the Four Enantiomerically Pure Diasteroisomers of the Phytoprostanes E1Type II and of the 15-E2t-Isoprostanes. J. Org. Chem. 2008, 73 (8), 3063-9.

(24) Pinciroli, M.; Domínguez-Perles, R.; Abellán, A.; Guy, A.; Durand, T.; Oger, C.; Galano, J. M.; Ferreres, F.; Gil-Izquierdo, A. Comparative Study of the Phytoprostane and Phytofuran Content of indica and japonica Rice (Oryza sativa L.) Flours. J. Agric. Food Chem. 2017, 65, 8938-8947.

(25) Collado-González, J.; Medina, S.; Durand, T.; Guy, A.; Galano, J.-M.; Torrecillas, A.; Ferreres, F.; Gil-Izquierdo, A. New UHPLC-QqQ-MS/MS method for quantitative and qualitative determination of free phytoprostanes in foodstuffs of commercial olive and sunflower oils. Food Chem. 2015, 178, 212-220.

(26) Dominguez-Perles, R.; Abellan, A.; Leon, D.; Ferreres, F.; Guy, A.; Oger, C.; Galano, J. M.; Durand, T.; Gil-Izquierdo, A. Sorting out the phytoprostane and phytofuran profile in vegetable oils. Food Res. Int. 2018, 107, 619-628.

(27) Barbosa, M.; Collado-Gonzalez, J.; Andrade, P. B.; Ferreres, F.; Valentao, P.; Galano, J. M.; Durand, T.; Gil-Izquierdo, A. Nonenzymatic alpha-Linolenic Acid Derivatives from the Sea: Macroalgae as Novel Sources of Phytoprostanes. J. Agric. Food Chem. 2015, 63 (28), 6466-74

(28) Carrasco-Del Amor, A.; Collado-Gonzalez, J.; Aguayo, E.; Guy, A.; Galano, J.; Durand, T.; Gil-Izquierdo, A. Phytoprostanes in almonds: identification, quantification, and impact of cultivar and type of cultivation. RSC Adv. 2015, 5 (63), 51233-51241.

(29) Yonny, M. E.; Rodríguez Torresi, A.; Cuyamendous, C.; Réversat, G.; Oger, C.; Galano, J.-M.; Durand, T.; Vigor, C.; Nazareno, M. A. Thermal Stress in Melon Plants: Phytoprostanes and Phytofurans as Oxidative Stress Biomarkers and the Effect of Antioxidant Supplementation. J. Agric. Food Chem. 2016, 64 (44), 8296-8304.

(30) Marhuenda, J.; Medina, S.; Díaz-Castro, A.; MartínezHernández, P.; Arina, S.; Zafrilla, P.; Mulero, J.; Oger, C.; Galano, J.-M.; Durand, T.; Ferreres, F.; Gil-Izquierdo, A. Dependency of Phytoprostane Fingerprints of Must and Wine on Viticulture and Enological Processes. J. Agric. Food Chem. 2015, 63 (41), 9022-9028.

(31) Collado-Gonzalez, J.; Perez-Lopez, D.; Memmi, H.; Gijon, M. C.; Medina, S.; Durand, T.; Guy, A.; Galano, J. M.; Ferreres, F.; Torrecillas, A.; Gil-Izquierdo, A. Water deficit during pit hardening enhances phytoprostanes content, a plant biomarker of oxidative stress, in extra virgin olive oil. J. Agric. Food Chem. 2015, 63 (14), 3784-92.

(32) Enyedi, A. J.; Yalpani, N.; Silverman, P.; Raskin, I. Localization, conjugation, and function of salicylic acid in tobacco during the hypersensitive reaction to tobacco mosaic virus. Proc. Natl. Acad. Sci. U. S. A. 1992, 89 (6), 2480-2484.

(33) Cuyamendous, C.; de la Torre, A.; Lee, Y. Y.; Leung, K. S.; Guy, A.; Bultel-Ponce, V.; Galano, J. M.; Lee, J. C.; Oger, C.; Durand, T. The novelty of phytofurans, isofurans, dihomo-isofurans and neurofurans: Discovery, synthesis and potential application. Biochimie 2016, 130, 49-62.

(34) Le Gall, H.; Philippe, F.; Domon, J. M.; Gillet, F.; Pelloux, J.; Rayon, C. Cell Wall Metabolism in Response to Abiotic Stress. Plants 2015, 4 (1), 112-66.

(35) Arshad, M. S.; Farooq, M.; Asch, F.; Krishna, J. S. V.; Prasad, P. V. V.; Siddique, K. H. M. Thermal stress impacts reproductive development and grain yield in rice. Plant Physiol. Biochem. 2017, 115, $57-72$.

(36) Yoshida, S.; Hara, T. Effects of air temperature and light on grain filling of an indica and a japonica rice (Oryza sativa L.) under controlled environmental conditions. Soil Sci. Plant Nutr. 1977, 23, 93-107.

(37) Wakamatsu, K.-i.; Sasaki, O.; Uezono, I.; Tanaka, A. Effects of High Air Temperature during the Ripening Period on the Grain Quality of Rice in Warm Regions of Japan. Nippon Sakumotsu Gakkai Kiji 2007, 76 (1), 71-78.

(38) Riga, P.; Medina, S.; Garcia-Flores, L. A.; Gil-Izquierdo, A. Melatonin content of pepper and tomato fruits: effects of cultivar and solar radiation. Food Chem. 2014, 156, 347-52.

(39) Li, X.; Wu, L.; Geng, X.; Xia, X.; Wang, X.; Xu, Z.; Xu, Q. Deciphering the Environmental Impacts on Rice Quality for Different Rice Cultivated Areas. Rice (New York, N.Y.) 2018, 11 (1), 7.

(40) Clarke, S. M.; Mur, L. A.; Wood, J. E.; Scott, I. M. Salicylic acid dependent signaling promotes basal thermotolerance but is not 
essential for acquired thermotolerance in Arabidopsis thaliana. Plant $J$. 2004, 38 (3), 432-47.

(41) Collado-González, J.; Pérez-López, D.; Memmi, H.; Gijón, M. C.; Medina, S.; Durand, T.; Guy, A.; Galano, J. M.; Fernández, D. J.; Carro, F.; et al. Effect of the season on the free phytoprostane content in Cornicabra extra virgin olive oil from deficit-irrigated olive trees. J. Sci. Food Agric. 2016, 96 (5), 1585-1592.

(42) Jahn, U.; Galano, J. M.; Durand, T. A cautionary note on the correct structure assignment of phytoprostanes and the emergence of a new prostane ring system. Prostaglandins, Leukotrienes Essent. Fatty Acids 2010, 82 (2-3), 83-6.

(43) Karg, K.; Karg, K.; Dirsch, V. M.; Karg, K.; Dirsch, V. M.; Vollmar, A. M.; Cracowski, J.-L.; Laporte, F.; Mueller, M. J. Biologically active oxidized lipids (phytoprostanes) in the plant diet and parenteral lipid nutrition. Free Radical Res. 2007, 41 (1), 25-37. (44) Collado-González, J.; Durand, T.; Ferreres, F.; Medina, S.; Torrecillas, A.; Gil-Izquierdo, A. Phytoprostanes. Lipid Technol. 2015, 27, 127-130. 